J. Lake Sci. (湖泊科学) , 2011, 23(4): 555-560

http: //www. jlakes. org. E-mail : jlakes@niglas.ac.cn

(C) 2011 by Journal of Lake Sciences

\title{
南四湖沼泽化现状及其驱动因素分析”
}

\author{
兰书斌 ${ }^{1,2}$, 吴 丽 $^{1,2}$, 张德禄 ${ }^{1,3}$, 胡春香 $^{1 * *}$ \\ (1:中国科学院水生生物研究所,武汉 430072) \\ (2: 中国科学院研究生院, 北京 100049 ) \\ $(3$ :武汉理工大学生物科学与技术系,武汉 430070)
}

摘 要: 为了解南四湖近几年沼泽化加剧的现状及其根源, 2008 年 8 月,2009 年 6 月,2009 年 8 月,2010 年 6 月和 2010 年 8 月先后多次对南四湖全湖, 及 21 条主要人湖河道河口区进行调查和采样分析. 结果表明: 调查的 25 个样点中除微山 岛保护区附近和船舶密集的界河口附近 4 个样点无沼泽化表征, 运输繁忙的老万福河人湖口和南阳湖敞水区 2 个样点为 轻度沼泽化外, 其它样点中 6 个中度沼泽化, 12 个重度沼泽化, 1 个极重度沼泽化; 沼泽化程度与植被类型、淤泥深度和淤 泥有机质含量呈显著正相关, 与 $\mathrm{pH}$ 和溶解氧呈显著负相关; 而植被丰度与水深、 $\mathrm{pH}$ 和溶解氧呈显著负相关; 淤积程度与 $\mathrm{TN} 、 \mathrm{TP} 、$ 淤泥有机质呈显著正相关, 与 COD 呈显著负相关. 因此, 局部表征上是外源污染物的输人和湖泊营养水平的提高 导致了沼泽化,但整体上是流域水资源的不合理利用进一步加剧了沼泽化的进程.

关键词: 南四湖; 沼泽化现状; 驱动因素

\section{On the terrestrialization situation and its driving factors in Lake Nansi}

\author{
LAN Shubin ${ }^{1,2}$, WU Li ${ }^{1,2}$, ZHANG Delu ${ }^{1,3} \&$ HU Chunxiang ${ }^{1}$ \\ ( 1: Institute of Hydrobiology, Chinese Academy of Sciences, Wuhan 430072, P. R. China) \\ (2: Graduate School of Chinese Academy of Sciences, Beijing 100049, P. R. China) \\ (3: Department of Biological Science and Biotechnology, Wuhan University of Technology, Wuhan 430070, P. R. China)
}

\begin{abstract}
In order to comprehend the terrestrialization situation and its driving factors in Lake Nansi, the whole Lake Nansi and 21 inlets of the rivers entering the lake were sampled and investigated in August 2008, June 2009, August 2009, June 2010 and August 2010. The results showed that only 4 sites located in the Natural Reserve of Weishan Island and the inlet of Jiehe River with dense shipping belonged to no terrestrialization, 2 sites lying the inlet of Laowanfu River with busy transport and the open water region of Nanyang Lake to slight terrestrialization, other 6 sites were moderate terrestrialization, 12 sites severe terrestrialization and 1 site heavy severe terrestrialization among the 25 sampling sites. The degree of terrestrialization was significantly positively correlated to vegetation types, depth and organic matter content of silt, negatively correlated to $\mathrm{pH}$ and dissolved oxygen; the abundance of vegetation was close negatively correlated to depth of water, $\mathrm{pH}$ and dissolved oxygen; the silting level was positively to total nitrogen, total phosphorus, organic matter of sediment, negatively to chemical oxygen demand. So apparently the import of exogenous contamination and increase of trophic level promoted the terrestrialization speed, and the unreasonable development in the whole drainage area further accelerated this progress.
\end{abstract}

Keywords: Lake Nansi; terrestrialization situation; driving factor

南四湖是南阳湖、独山湖、昭阳湖和微山湖由北向南相连而成的湖泊总称, 位于淮河流域北部. 全湖南 北长 $126 \mathrm{~km}$, 东西宽 5-25km, 中部最窄, 湖面面积 $1266 \mathrm{~km}^{2}$, 流域面积 $31700 \mathrm{~km}^{2}$, 年平均人湖径流量 $29160 \times$ $10^{8} \mathrm{~m}^{3}$, 年平均出湖径流量 $19120 \times 10^{8} \mathrm{~m}^{3}$. 在行政区划上隶属山东省济宁市微山县, 湖区内有农田和鱼塘 300

* 国家水体污染控制与治理科技重大专项项目 (2009ZX07210-009) 资助. 2010-09-08 收稿; 2010-12-07 收修改 稿. 兰书斌,男,1984 年生, 博士研究生;E-mail:shblan@ 163. com.

** 通讯作者;E-mail: cxhu@ihb. ac. cn. 
余平方千米, 居住着 10 余万农民和渔民, 是山东省最大的湖泊, 也是我国第六大淡水湖泊. 京杭运河南北纵 贯全湖, 把南北江河水系交汇沟通. 1958 年在此建成了拦湖大坝, 坝上修建船闸和节水闸, 将湖一分为二. 坝 北为上级湖, 面积 $602 \mathrm{~km}^{2}$, 坝南为下级湖, 面积 $664 \mathrm{~km}^{2}$.

表 1 南四湖调查样点设置

Tab. 1 Characteristics of sampling sites in Lake Nansi

\begin{tabular}{|c|c|c|}
\hline 样点 & 地点特征 & 主要植被 \\
\hline 1 & 微山岛湿地公园周围 & 荷花、芦苇、荇菜 \\
\hline 2 & 微山湖敞水区 & 无 \\
\hline 3 & 蒋集河人湖口 & 芦苇、荇菜、空心莲子草 \\
\hline 4 & 十字河人湖口 & 荷花、狐尾藻、苦草 \\
\hline 5 & 薛河人湖口 (艾湖村附近) & 荷花、芦苇、空心莲子草 \\
\hline 6 & 鹿口河人湖口 & 荇菜、芦苇、马莱眼子菜 \\
\hline 7 & 沿河人湖口 (赵庙港附近) & 芦苇、荇菜、苦草 \\
\hline 8 & 纸厂河人湖口(西港附近) & 无 \\
\hline 9 & 二级坝下游 & 荇菜、马莱眼子菜 \\
\hline 10 & 西支河人湖口 & 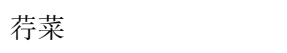 \\
\hline 11 & $\begin{array}{l}\text { 东鱼河人湖口, } \\
2005 \text { 年清过淤泥 }\end{array}$ & 荷花、菱、狐尾藻 \\
\hline 12 & 复兴河人湖口 & 浮萍 \\
\hline 13 & 大沙河人湖口 & 浮萍 \\
\hline 14 & 独山湖湖区围网周围 & 无 \\
\hline 15 & 界河人湖口 & 无 \\
\hline 16 & 北沙河人湖口 & 芦苇、荷花、香蒲 \\
\hline 17 & 郭河人湖口 ( 郭城港附近) & 芦苇、荷花、空心莲子草 \\
\hline 18 & 惠河人湖口 & 水鳖、空心莲子草 \\
\hline 19 & 老万福河人湖口 & 苦草、水鳖 \\
\hline 20 & 新万福河人湖口 & 芦苇 \\
\hline 21 & 洙赵新河人湖口 & 芦苇、荇菜 \\
\hline 22 & 梁济运河人湖区 & 芦苇 \\
\hline 23 & 泗河人湖口 & 芦苇 ～～～～～～～ \\
\hline 24 & 白马河人湖口 & 芦苇、空心莲子草、荇菜 \\
\hline 25 & 南阳镇周围敞水区 & 马莱眼子菜、苦草 \\
\hline
\end{tabular}

南四湖是我国著名的大型淡水湖泊之一. 它既是供百万亩稻田灌溉的淡水水源,也是重 要水产品的生产基地; 同时又是沿湖工农业发 展、城镇居民生活及航运的重要水资源; 还是南 水北调东线调水工程中重要的调蓄库,综合效 益显著. 然而近十几年来,由于沿湖地区工、农、 渔业的迅速发展, 湖区资源的过度开发利用, 水 环境状况日趋恶化,主要表现在水污染加重, 湖 底淤积加剧, 富营养化程度加重 ${ }^{[1]}$. 加上 2002 年 从黄河和长江的几次调水, 大量泥沙的人湖使 淤泥的沉积和沼泽化进一步加重, 调蓄能力明 显下降 ${ }^{[2]}$. 湖泊的沼泽化是指在历史沉积、水文 变动、地质变迁等过程中, 湖泊沉积物增厚, 水 深变浅,水草增长的现象. 沼泽化的后果不仅直 接影响水资源的利用,还影响湖区及周边的生 态环境和社会经济发展, 更可能导致湖泊的消 亡. 目前国内对湖泊沼泽化的重视程度很不够, 对沼泽化的量化研究还处于探索阶段 ${ }^{[3]}$. 因此, 开展即将承担国家调水工程调蓄任务的南四湖 的沼泽化调查意义重大.

\section{1 材料与方法}

2008 年 6 月, 2009 年 6 月, 2009 年 8 月, 2010 年 6 月及 2010 年 8 月先后对全湖 25 处样 点进行调查 (表 1, 图 1). 由于调查结果的相似 性, 为反映最近南四湖的沼泽化状况, 本文主要 采用 2010 年 8 月 $12-14$ 日期间水草最丰富的数 据, 样点采用 GPS 精确定位. 对各样点的主要湖 沼学特征进行了现场测定. 其中水深、透明度用 透明度盘测定; 淤泥深度用竹笔测定; 植被类型 目测; 水温、总溶解固体、 $\mathrm{pH}$ 值、盐度、电导率和

溶解氧用 YSI-Proplus 型多参数水质分析仪进行测定. 同时对各样点的水体和泥样进行采集, 测定叶绿素 a、 总氮 $(\mathrm{TN})$ 、总磷 $(\mathrm{TP})$ 、化学需氧量 $\left(\mathrm{COD}_{\mathrm{Cr}}\right)$ 、悬浮物、淤泥有机质、淤泥 TN 和 TP 含量. 水样采集用采水器在 水面下 $50 \mathrm{~cm}$ 处采集, 泥样用采泥器采集, 水样和泥样装人聚乙烯塑料瓶中运回实验室测定, 相关指标的测 定方法参照《水和废水监测分析方法》 ${ }^{[4]}$ 和《湖泊富营养化调查规范》 ${ }^{[5]}$.

沼泽化程度的植被指标 $V_{z \mathrm{hh}}$ 按照吴庆龙等 ${ }^{[3]}$ 的方法分为四个基本级别, 并且 $V_{z \mathrm{zh}}=\{0,1,2,3\}$, 其中 0 代表 无大型植物; $1,2,3$ 分别代表沉水植物、浮叶植物和挺水植物占优势. 淤积指标 $D_{z \mathrm{zh}}=\left(h-h_{1}\right) /\left(h_{2}-h_{1}\right)$, 其 中, $h_{1}, h_{2}$ 为最小和最大淤泥深度; $h$ 为调查样点某一点的淤泥深度. 沼泽化程度的综合指标 $S_{z \mathrm{hh}}=V_{z \mathrm{hh}}+D_{z \mathrm{zh}}$.

富营养化程度选取叶绿素 $\mathrm{a} 、 T N 、 T P 、 C O D D_{\mathrm{Cr}}$ 和透明度五个指标, 用综合营养状态指数 $T S I$ 进行评价, TSI = $W_{\text {Chl a }} \times T S I_{\mathrm{Chl} . \mathrm{a}}+W_{\mathrm{TN}} \times T S I_{\mathrm{TN}}+W_{\mathrm{TP}} \times T S I_{\mathrm{TP}}+W_{\mathrm{COD}} \times T S I_{\mathrm{COD}}+W_{\mathrm{SD}} \times T S I_{\mathrm{SD}}$, 其中 $W_{\mathrm{Chl} . \mathrm{a}} 、 W_{\mathrm{TN}} 、 W_{\mathrm{TP}} 、 W_{\mathrm{COD}}$ 和 $W_{\mathrm{SD}}$ 分别 为叶绿素 $\mathrm{a} 、 \mathrm{TN} 、 \mathrm{TP} 、 \mathrm{COD}_{\mathrm{Cr}}$ 和透明度的相关权重; $T S I_{\mathrm{Chl} \text { a } 、} T S I_{\mathrm{TN}} 、 T S I_{\mathrm{TP}} 、 T S I_{\mathrm{COD}}$ 和 $T S I_{\mathrm{SD}}$ 分别为叶绿素 $\mathrm{a} 、 T N 、 T P 、$ 


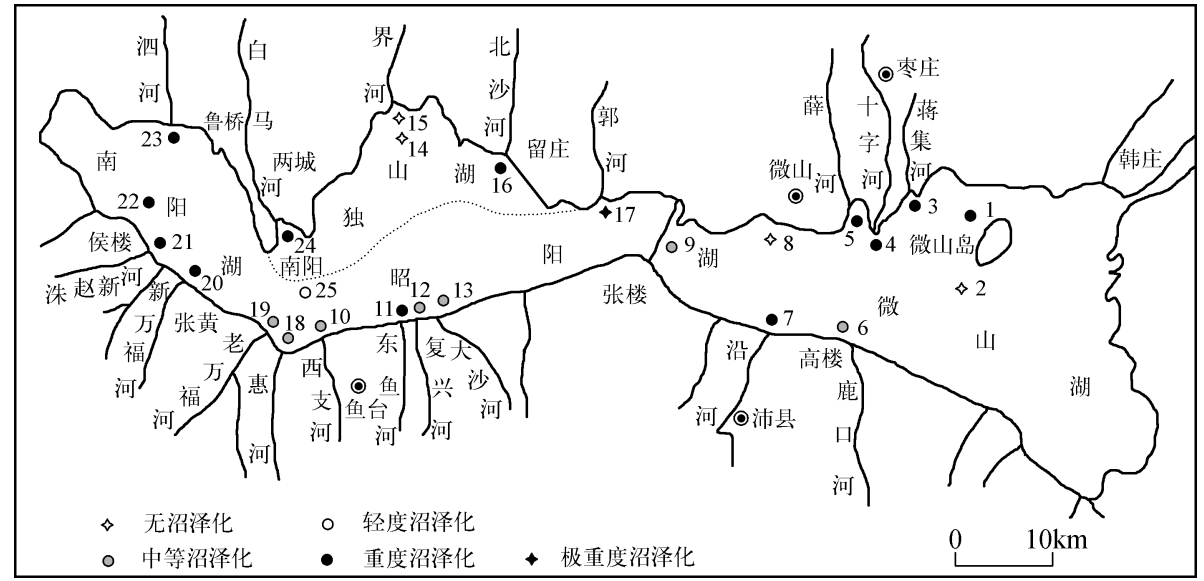

图 1 各样点沼泽化及分布情况

Fig. 1 The terrestrialization situation and distribution of each site

$\mathrm{COD}_{\mathrm{Cr}}$ 和透明度的营养状态指数. 以叶绿素 a 作为基准, $W_{i}=r_{i}{ }^{2} / R$, 其中 $W_{i}$ 为指标 $i$ 的相关权重, $r_{i}$ 为指标 $i$ 与叶绿素 $\mathrm{a}$ 之间的相关系数; $R$ 为 5 个指标与叶绿素 $\mathrm{a}$ 之间相关系数的平方和;每个指标的营养状态指数计 算参照 Carlson ${ }^{[6]}$ 及《湖泊富营养化调查规范》 ${ }^{[5]}$ 所描述的方法.

对沼泽化指标的聚类用 Hierarchical Cluster Analysis 进行分析;沼泽化指标与环境因子之间的相关性用 Bivariate Correlations 进行分析. 所有分析在 SPSS 13.0 软件 上进行.

\section{2 结果}

\section{1 南四湖沼泽化以及分布情况}

调查结果显示, 沉水植物主要有: 马莱眼子菜 $($ Potamogeton malaianus)、苦草 (Vallisneria natans)、狐尾藻 (Myriophyllum verticillatum); 浮叶植物主要有: 荷花 (Nelumbo nucifera)、菱 ( Trapa bispinosa $) 、$ 荇菜 ( Nymphoides peltatum); 漂浮植物主要是浮萍 (Lemna minor L. )、水鳖 (Hydrocharis dubia); 挺水植物主要有: 芦苇 (Phragmites australis)、空心莲子草(Alternanthera philoxeroides)、香蒲( Typha orientalis).

所有调查样点中, 淤泥深度在 $20-220 \mathrm{~cm}$ 之间, 平均 为 $55.4 \mathrm{~cm}$. 微山岛湿地公园、十字河 (老运河口) 、郭河、 东鱼河、老万福河、新万福河、泗河 (运煤) 等 $28 \%$ 的区域 中淤泥深度在 $70 \mathrm{~cm}$ 以上. 全湖沼泽化淤积指标在 $0-1$ 之间,综合指标在 0-4 之间 (表 2). 通过对 25 个样点的 沼泽化指标进行聚类发现,微山岛保护区附近和船舶密 集的界河口附近四个样点 (样点 $2,8,14,15$ ) 属一类, 沼 泽化综合指标在 $0.07-0.10$ 之间, 为无沼泽化区域; 老 万福河人湖口和南阳镇周围敞水区 (样点 19,25 ) 属一 类,沼泽化综合指标在 $1.15-1.25$ 之间, 为轻度沼泽化 区域; 鹿口河、西支河、复兴河、大沙河、惠河人湖口和二
表 2 南四湖沼泽化情况

Tab. 2 Terrestrialization situation in Lake Nansi

\begin{tabular}{cccc}
\hline 样点 & 植被指标 & 淤积指标 & 综合指标 \\
\hline 1 & 3 & 0.250 & 3.250 \\
2 & 0 & 0.075 & 0.075 \\
3 & 3 & 0.115 & 3.115 \\
4 & 3 & 0.250 & 3.250 \\
5 & 3 & 0.175 & 3.175 \\
6 & 2 & 0.125 & 2.125 \\
7 & 3 & 0.125 & 3.125 \\
8 & 0 & 0.100 & 0.100 \\
9 & 2 & 0.125 & 2.125 \\
10 & 2 & 0.025 & 2.025 \\
11 & 3 & 0.300 & 3.300 \\
12 & 2 & 0.000 & 2.000 \\
13 & 2 & 0.035 & 2.035 \\
14 & 0 & 0.100 & 0.100 \\
15 & 0 & 0.075 & 0.075 \\
16 & 3 & 0.110 & 3.110 \\
17 & 3 & 1.000 & 4.000 \\
18 & 2 & 0.140 & 2.140 \\
19 & 1 & 0.250 & 1.250 \\
20 & 3 & 0.300 & 3.300 \\
21 & 3 & 0.050 & 3.050 \\
22 & 3 & 0.150 & 3.150 \\
23 & 3 & 0.300 & 3.300 \\
24 & 3 & 0.100 & 3.100 \\
25 & 1 & 0.150 & 1.150 \\
\hline & 3 & &
\end{tabular}


级坝下游(样点 $6,9,10,12,13,18$ ) 属一类, 沼泽化综合指标在 $2.00-2.14$ 之间, 为中度沼泽化区域;微山岛 湿地公园周围、蒋集河、十字河、薛河、沿河、东鱼河、北沙河、新万福河、洙赵新河、泗河、白马河人湖口和梁 济运河人湖区 (样点 $1 、 3 、 4 、 5 、 7 、 11 、 16 、 20 、 21 、 22 、 23 、 24$ ) 属一类, 沼泽化综合指标在 $3.05-3.30$ 之间, 为重 度沼泽化区域; 郭河人湖口 (样点 17 ) 单独为一类, 沼泽化综合指标为 4 , 为极重度沼泽化区域 (图 1 ).

\section{2 富营养化}

各样点的叶绿素 $\mathrm{a} 、 T N 、 T P 、 C O D$ 和透明度值见表 3 , 其中叶绿素 $\mathrm{a}$ 范围为 $0.009-0.070 \mathrm{mg} / \mathrm{L}$, 平均值为 $0.031 \mathrm{mg} / \mathrm{L}$; TN 范围为 $0.043-7.294 \mathrm{mg} / \mathrm{L}$, 平均值为 $1.065 \mathrm{mg} / \mathrm{L}$; TP 范围为 $0.015-0.200 \mathrm{mg} / \mathrm{L}$, 平均值为 $0.048 \mathrm{mg} / \mathrm{L} ; \mathrm{COD}$ 范围为 $9.101-29.577 \mathrm{mg} / \mathrm{L}$, 平均值为 $18.110 \mathrm{mg} / \mathrm{L} ; \mathrm{SD}$ 范围为 $0.2-0.7 \mathrm{~m}$, 平均值为 $0.4 \mathrm{~m}$. 利用上述 5 个指标计算出各样点 $T S I$, 其中综合营养状态指数在 50-60 之间为中-富营养, 包括微山岛湿地 公园周围、二级坝下游、十字河、鹿口河、沿河、东鱼河、北沙河、郭河、老万福河人湖口和独山湖湖区围网周 围( 样点 $1 、 4 、 6 、 7 、 9 、 11 、 14 、 16 、 17 、 19 、 24$ 和 25 ); 综合营养状态指数在 $60-70$ 之间为富营养, 包括微山湖敞 水区、蒋集河、薛河、纸厂河、西支河、大沙河、界河、惠河、新万福河、洙赵新河、泗河人湖口和梁济运河人湖 区 (样点 $2 、 3 、 5 、 8 、 10 、 13 、 15 、 18 、 20 、 21 、 22$ 和 23$)$; 综合营养状态指数 $>70$ 为重富营养, 包括复兴河人湖口 (样点 12 ) (表 3 ).

表 3 各样点富营养化程度

Tab. 3 The trophic state of each site

\begin{tabular}{|c|c|c|c|c|c|c|c|}
\hline 样点 & $\begin{array}{c}\text { 叶绿素 a } \\
(\mathrm{mg} / \mathrm{L})\end{array}$ & $\begin{array}{c}\mathrm{TN} \\
(\mathrm{mg} / \mathrm{L})\end{array}$ & $\begin{array}{c}\mathrm{TP} \\
(\mathrm{mg} / \mathrm{L})\end{array}$ & $\begin{array}{c}\text { COD } \\
(\mathrm{mg} / \mathrm{L})\end{array}$ & $\begin{array}{l}\mathrm{SD} \\
(\mathrm{m})\end{array}$ & TSI & $\begin{array}{c}\text { 富营养化 } \\
\text { 程度 }\end{array}$ \\
\hline 1 & 0.012 & 0.595 & 0.029 & 22.752 & 0.23 & 56.091 & 中-富营养 \\
\hline 2 & 0.038 & 0.073 & 0.023 & 15.926 & 0.40 & 60.066 & 富营养 \\
\hline 3 & 0.067 & 0.199 & 0.057 & 27.302 & 0.32 & 68.420 & 富营养 \\
\hline 4 & 0.011 & 0.253 & 0.061 & 20.476 & 0.50 & 53.309 & 中-富营养 \\
\hline 5 & 0.032 & 1.166 & 0.033 & 15.926 & 0.50 & 63.611 & 富营养 \\
\hline 6 & 0.012 & 0.839 & 0.035 & 9.101 & 0.40 & 53.213 & 中-富营养 \\
\hline 7 & 0.013 & 0.131 & 0.019 & 25.027 & 0.37 & 54.252 & 中-富营养 \\
\hline 8 & 0.024 & 1.283 & 0.053 & 18.201 & 0.30 & 62.110 & 富营养 \\
\hline 9 & 0.012 & 0.873 & 0.019 & 11.376 & 0.33 & 54.140 & 中-富营养 \\
\hline 10 & 0.056 & 0.419 & 0.031 & 15.926 & 0.20 & 66.447 & 富营养 \\
\hline 11 & 0.028 & 0.077 & 0.023 & 15.926 & 0.55 & 57.656 & 中-富营养 \\
\hline 12 & 0.070 & 0.707 & 0.045 & 22.752 & 0.20 & 70.475 & 重富营养 \\
\hline 13 & 0.055 & 0.097 & 0.047 & 29.577 & 0.43 & 65.785 & 富营养 \\
\hline 14 & 0.032 & 0.058 & 0.029 & 20.476 & 0.37 & 59.231 & 中-富营养 \\
\hline 15 & 0.043 & 0.351 & 0.033 & 20.476 & 0.50 & 64.737 & 富营养 \\
\hline 16 & 0.011 & 1.980 & 0.015 & 15.926 & 0.50 & 56.049 & 中-富营养 \\
\hline 17 & 0.013 & 6.040 & 0.200 & 9.101 & 0.45 & 57.381 & 中-富营养 \\
\hline 18 & 0.021 & 0.717 & 0.047 & 22.752 & 0.20 & 60.918 & 富营养 \\
\hline 19 & 0.020 & 0.658 & 0.063 & 15.926 & 0.20 & 59.070 & 中-富营养 \\
\hline 20 & 0.033 & 1.214 & 0.055 & 15.926 & 0.30 & 64.055 & 富营养 \\
\hline 21 & 0.064 & 0.082 & 0.063 & 18.201 & 0.50 & 64.875 & 富营养 \\
\hline 22 & 0.052 & 0.043 & 0.053 & 15.926 & 0.50 & 61.574 & 富营养 \\
\hline 23 & 0.043 & 0.995 & 0.061 & 18. 201 & 0.30 & 66.298 & 富营养 \\
\hline 24 & 0.010 & 7.294 & 0.051 & 18.201 & 0.37 & 58.203 & 中-富营养 \\
\hline 25 & 0.009 & 0.482 & 0.043 & 11.376 & 0.70 & 50.623 & 中-富营养 \\
\hline
\end{tabular}




\section{3 沼泽化与环境因子}

通过沼泽化指标与环境因子之间 的相关性分析发现 (表 4), 植被指标与 水深、 $\mathrm{pH}$ 和溶解氧呈显著负相关; 淤积 指标与 TN 、TP 呈显著正相关, 与 $\mathrm{COD}$ 呈显著负相关; 综合指标与植被类型、 淤泥深度和淤泥有机质呈显著正相关， 与 $\mathrm{pH}$ 和溶解氧呈显著负相关.

\section{3 讨论}

\section{1 沼泽化调查的季节性}

湖泊有其生成、发展和消亡的自然 过程,但自然情况下生态系统的演化很 漫长. 一般的过程是: 湖泊经过长期的 物理、化学以及生物沉积, 湖水逐渐变 浅,在光照、温度等条件适宜处,喜水的 维管植物开始生长. 后来枯萎的植物枝 体不断地堆积在湖底,而在湖底缺氧条 件下这些残体分解缓慢,经过长期的累 积,沉积底泥中的有机质含量逐渐增 加. 随着底泥淤积的增厚, 湖水进一步 变浅,挺水植物开始疯长, 从而使湖泊 向沼泽演变. 因此,湖泊的沼泽化是一 个自然演替的过程,但人类活动的不断 干扰可使其生命周期迅速缩短 ${ }^{[7]}$. 在对 南四湖的研究中发现,8 月湖泊 $52 \%$ 的
表 4 沼泽化指标与环境因子之间的相关性分析

Tab. 4 Correlation analysis between terrestrialization indices and environment factors

\begin{tabular}{|c|c|c|c|c|c|c|}
\hline \multirow{2}{*}{ 环境因子 } & \multicolumn{2}{|c|}{ 植被指标 } & \multicolumn{2}{|c|}{ 淤积指标 } & \multicolumn{2}{|c|}{ 综合指标 } \\
\hline & $R$ & $P$ & $R$ & $P$ & $R$ & $P$ \\
\hline 植被类型 & 1.000 & $<0.001^{* *}$ & 0.327 & 0.111 & 0.989 & $<0.001^{* *}$ \\
\hline 水深 & -0.407 & $0.044^{*}$ & -0.087 & 0.680 & -0.395 & 0.051 \\
\hline 水温 & -0.265 & 0.201 & 0.282 & 0.172 & -0.203 & 0.331 \\
\hline 透明度 & -0.102 & 0.627 & 0.111 & 0.599 & -0.078 & 0.711 \\
\hline 总溶解固体 & 0.239 & 0.249 & -0.205 & 0.325 & 0.191 & 0.359 \\
\hline 悬浮物 & 0.254 & 0.221 & -0.161 & 0.441 & 0.212 & 0.310 \\
\hline $\mathrm{pH}$ & -0.586 & $0.002^{* *}$ & $"-0.159$ & 0.447 & -0.574 & $0.003^{* *}$ \\
\hline 盐度 & 0.247 & 0.234 & -0.196 & 0.347 & 0.200 & 0.338 \\
\hline 电导率 & 0.235 & 0.258 & -0.208 & 0.318 & 0.187 & 0.371 \\
\hline 溶解氧 & -0.572 & $0.003^{* *}$ & -0.203 & 0.330 & -0.568 & $0.003^{* *}$ \\
\hline COD & 0.053 & 0.802 & -0.413 & $0.040 *$ & -0.016 & 0.938 \\
\hline $\mathrm{TN}$ & 0.231 & 0.266 & 0.511 & $0.009^{* *}$ & $* 0.298$ & 0.148 \\
\hline $\mathrm{TP}$ & 0.237 & 0.254 & 0.842 & $<0.001^{* *}$ & $* 0.356$ & 0.081 \\
\hline 叶绿素 a & -0.075 & 0.723 & -0.356 & 0.081 & -0.127 & 0.547 \\
\hline 淤泥深度 & 0.327 & 0.111 & 1.000 & $<0.001^{* *}$ & $* 0.466$ & $0.019^{*}$ \\
\hline 淤泥有机质 & 0.327 & 0.111 & 1.000 & $<0.001^{* *}$ & $* 0.466$ & $0.019^{*}$ \\
\hline 淤泥 TN & 0.195 & 0.351 & 0.152 & 0.467 & 0.206 & 0.322 \\
\hline 淤泥 TP & -0.136 & 0.518 & -0.345 & 0.091 & -0.182 & 0.384 \\
\hline
\end{tabular}

* 代表相关性显著 $(P<0.05)$; **代表相关性极显著 $(P<0.01)$.

样点属于重度沼泽化,而在 6 月的结果中只有 $25 \%$ 的样点为重度沼泽化. 其根本原因是在不同的季节植被 生长状况不同,但维管植被的丰富度是衡量沼泽化的重要指标, 在采用的沼泽化综合指标计算公式中 ${ }^{[3]}$ 植 被状况占总信息量的 $75 \%(R=0.989, P<0.001)$,而淤积只占 $25 \%$. 事实也是如此,在沼泽化的定义中,没 有维管植被疯长的水域变浅不是真正的沼泽化, 只需清淤或疏浚就可使其恢复原貌; 而一旦植被疯长, 就意 味着整个水生态系统受到了严重破坏, 这不是简单的机械清淤或清除植被就能够解决的, 因为植被疯长与 底泥淤积、水的富营养化等密切关联. 因此,研究或评价湖泊沼泽化就应该在水草最丰富的季节进行调查和 取样.

\section{2 沼泽化的物质基础}

南四湖东部的本底中就有大量随山洪、径流带人的周缘丘陵带泥沙,加上湖西平原排洪河道在引黄退 水过程中也带来了大量泥沙,这样使全年人湖泥沙量达 $7.8 \times 10^{6} \mathrm{t}$, 年淤积量占湖泊总容量的 $0.13 \%^{[1]}$. 而我 们在平水期的研究中并未发现悬浮物与沼泽化之间存在显著相关性 $(P<0.05)$, 因此,这个结果进一步确定 了淤积的沉积物主要是雨季或暴雨期间随山洪、地表径流及引水济湖时带人的. 另外,我们发现运沙、运煤 (尤其是煤泥) 的船舶同样带人大量的泥沙沉积物,而且这在郭河非常明显,欢城煤矿大量的煤泥经郭城港 向外运输,使该地的淤泥沉积达 $220 \mathrm{~cm}$,芦苇几乎覆盖附近的全部湖面.

另外,南四湖的人湖河流都不同程度地受到了生活污水、工业废水、农田及鱼塘排水的污染, 这些水中 富含氮、磷等营养物质, 流人湖区加剧了水体的富营养化程度 ${ }^{[8-9]}$. 研究也发现沼泽化的淤积与 TN 、TP 呈显 著正相关 $(P<0.01)$. 因为水体中富集的营养物一方面沉积进人底泥,另一方面为水生植被的生长提供了充 足的营养源. 水生植被的生长可进一步截留更多的沉积物 (包括大气尘降), 加上枯枝落叶的积累, 使富营养 
化程度进一步加深. 在此次调查中发现 25 个样点中 $48 \%$ 为中-富营养, $48 \%$ 为富营养, $4 \%$ 为重富营养, 南四 湖总体处于中-富营养向富营养化过渡的状态. 而 1996 年时南四湖为中营养水平 ${ }^{[10]}, 2009$ 年是中-富营养 水平 ${ }^{[11]}$. 由此看来, 南四湖的富营养化程度仍在加剧.

\section{3 湖水理化性质及水资源利用对沼泽化的影响}

金红华报道湖流和水深对沼泽化的影响较大 ${ }^{[7]}$. 湖流不仅影响沉积物的分布, 同时也影响沉积速率. 水 深与水生植物的分布和产量有密切的关系, 一般深水区不利于大型维管植物的生长, 随着水体变浅, 沉水植 物、浮叶植物、挺水植物逐渐成为优势种类, 而浅水区则更有利于挺水植物的生长 ${ }^{[12]}$. 我们也发现沼泽化植 被指标、淤积指标以及综合指标都与水深呈负相关, 但与淤积指标和综合指标相关性并不显著, 因为沼泽化 的本质就是湖泊变浅, 不断加剧的沼泽化自然与深度呈负相关. 另外我们还发现沼泽化植被指标以及综合 指标与湖水 $\mathrm{pH}$ 和溶解氧呈显著负相关, 表明沼泽化过程中植被生长以及淤泥的积累导致了水体 $\mathrm{pH}$ 以及溶 解氧的下降,所以,沼泽化水体中水生植被生长对水生态系统往往不利.

另一个重要的驱动因素是水资源的不合理利用. 在南四湖内围网、网箱、围堰、鱼塘占到湖面的 $93 \%$ 以 上, 即使在航道较宽敞的部分区域, 也因为底泥淤积和水速较缓, 生长着成片的野菱、藕、眼子菜、芦苇等, 它 们的生长进一步弱化了湖水的运动. 另一方面, 饵料的投放和围堰的沙土堆积使得更多的沉积物淤积, 大大 加速了沼泽化的进程.

综上所述, 南四湖已经不是真正意义上的湖泊, 而是水体基本不流动的航道, 处于中-富营养向富营养 化过渡的状态, 而且富营养化趋势仍在加剧. 其沼泽化的原因既有自然因素, 又有人为因素. 外源污染物的 输人和湖泊营养水平的提高导致其沼泽化, 而流域水资源的不合理利用进一步加剧了沼泽化. 这深刻反映 了湖泊水资源开发利用与生态保护之间日益激烈的矛盾. 因此, 研究南四湖沼泽化的现状和驱动因素不仅 是了解这一问题所必需的, 更是解决问题的前提.

\section{4 参考文献}

[ 1 ] 张祖陆,孙庆义,彭利民等. 南四湖地区水环境问题探析. 湖泊科学, 1999,11(1):86-90.

[2] 杨东海,张 晴,潘勇伟等. 山东省南四湖及其流域环境特征. 江苏环境科技,2004,17 (增刊) : 120-126.

[ 3 ] 吴庆龙, 胡耀辉, 李文朝等. 东太湖沼泽化发展趋势及驱动因素分析. 环境科学学报, 2000,20(3):275-279.

[ 4 ] 国家环境保护总局《水和废水监测分析方法》编委会. 水和废水监测分析方法. 北京: 中国环境科学出版社,2002.

[ 5 ] 金相灿, 屠清瑛. 湖泊富营养化调查规范. 北京: 中国环境科学出版社, 1990.

[ 6 ] Carlson RE. A trophic state index for lakes. Limnology and Oceanography, 1977, 22: 361-369.

[ 7 ] 金红华. 浅水湖泊沼泽化程度定量评价及其在东太湖的应用 [ 学位论文].南京:河海大学, 2007.

[ 8 ] 武周虎,乔海涛,付莎莎等. 南水北调东线工程对南四湖环境的影响及对策. 青岛理工大学学报,2006,27(1):1-7.

[ 9 ] Wang C, Wang Y, Wang P. Water quality modeling and pollution control for the eastern route of South to North Water Transfer Project in China. Journal of Hydrodynamics, 2006, 18(3) : 253-261.

[10］舒金华,黄文钜,吴延根. 中国湖泊营养类型的分类研究. 湖泊科学, 1996,8(3):193-200.

[11] 徐祖信, 姜雅萍. 湖泊营养状态的综合水质标识指数评价及检验. 同济大学学报 (自然科学版), 2009, 37 (8): 1044-1048.

[12] 中国科学院南京地理研究所. 太湖综合调查初步报告. 北京: 科学出版社, 1965 . 